\title{
PRODUÇÃO DE LIGAS DE MEMÓRIA DE FORMA DE Ni-Ti- AI COM ELEMENTO LIGANTE DE NIÓBIO - RESULTADOS PARCIAIS
}

\section{PRODUCTION OF NI-TI-AL SHAPE MEMORY ALLOYS WITH TITANIUM BINDER -PARTIAL RESULTS}

I. C. CONCEIÇÃO ${ }^{1}$, L. C. M. DIAS ${ }^{1}$, A. M. FERNANDES ${ }^{1}$, R. L. P. TEIXEIRA ${ }^{1}$, F. M. FILHO $^{1}$, H. L. HASEGAWA ${ }^{1}$, J. C. de LACERDA ${ }^{2}$

${ }^{1}$ Universidade Federal de Itajubá, Departamento de Engenharia de Materiais, Brasil

${ }^{2}$ Universidade Federal de Itajubá, Departamento de Engenharia Mecânica, Brasil

E-mail: isabellacarolinaconceicao@gmail.com

\begin{abstract}
article info
Article history:

Received 2017-09-04

PALAVRAS-CHAVE: Nitinol; Forno a Plasma; Processo Skull; Memória de Forma; Ligante Accepted 2017-11-20 metálico de nióbio.

KEYWORDS: Nitinol; Plasma Oven; Skull Process; Shape Memory; Niobium metallic binder.

Available online 2017-12-20

RESUMO: Os materiais metálicos conhecidos como ligas com memória de forma (LMF) apresentam recuperação à sua forma original, depois de serem deformados por alguma carga aplicada, por meio de um tratamento térmico controlado. Dentre os materiais metálicos que apresentam EFM, destaca-se o nitinol (NiTi), que é uma liga equiatômica dos elementos metálicos de titânio e de níquel e que possui ampla aplicação. Neste trabalho, obtiveram-se algumas LMF com o acréscimo de alumínio metálico e de ligante metálico de nióbio ao nitinol. alumínio e o nióbio são materiais estabilizadores da fase $\alpha$ e da fase $\beta$ do titânio no nitinol, respectivamente. O processamento na obtenção das LMFs se deu por fusão em forno a plasma pelo processo Plasma Skull Push Pull (PSPP). Os tarugos de LMF produzidos e o nitinol foram caracterizados cristalográfica, química, mecânica e termicamente. Observou-se ainda que os elementos ligantes aumentam a dureza do material, fato relacionado, principalmente, a estabilização da fase martensita.
\end{abstract}

\begin{abstract}
Metallic materials known as shape memory alloys (SMAs) show recover into their original form, after being deformed by an applied charge, by means of a controlled heat treatment. Among metallic materials with shape memory effect SME, nitinol (NiTi), which is an equiatomic alloy of the metallic elements titanium and nickel, stands out due to its characteristics and properties, such as transformation temperature close to the environment, superelasticity, shape memory effect and good biocompatibility. In this work, some SMAs were obtained with the addition of metallic aluminum and metallic binder of niobium to nitinol. Aluminum and niobium are, respectively, stabilizing materials of the $\alpha$ phase and $\beta$ phase of titanium in nitinol. The processing in obtaining the SMAs consisted in melting using a plasma oven, through the process known as Plasma Skull Push Process (PSPP). The SMAs billets produced and the nitinol were crystallographically, chemically, mechanically and thermally characterized. It was also observed that the binder elements increase the hardness of the material, which is due, mainly to the stabilization of the martensite phase.
\end{abstract}




\section{INTRODUÇÃO}

As ligas com efeito de memória de forma (LMF) são materiais metálicos funcionais que podem se recuperar de grandes deformações pseudoplásticas quando submetidos a carregamentos mecânicos e/ou aquecimento. Aplicações das LMF estão ocorrendo em diversas áreas como aeroespacial, automotiva, telecomunicações, saúde, entre outras (LAGOUDAS, 2010).

O efeito de memória de forma está relacionado com as transformações martensíticas, que é a fase de baixa temperatura com estrutura com pouca simetria e muito deformável, e austenita, que é a fase de alta temperatura e dura. Com isso, tais ligas podem se transformar de martensita para austenita com o aquecimento, ou de austenita para martensita no seu resfriamento ou empregando-se um carregamento mecânico (OTSUKA, 2005).

Dentre as ligas com memória de forma, se destaca o nitinol, liga constituída dos metais de titânio e níquel em composições equiatômicas que possui ampla aplicação e interessantes propriedades como a biocompatibilidade, o que influi na gama de estudos voltados para áreas da saúde, além de próteses cirúrgicas (OTSUKA, 2005).

Contudo, mesmo com tamanho interesse em se desenvolver novas aplicações para esse material, o seu processamento e sua fabricação são complexos e ainda proporcionam alguns obstáculos como o difícil controle da composição química, alta reatividade do titânio em altas temperaturas e ainda, a necessidade de uma atmosfera completamente livre de impurezas (SIMÕES et al., 2015).

$\mathrm{Na}$ busca por alternativas de métodos de produção, o presente trabalho propôs a obtenção de uma liga com memória de forma com o próprio nitinol como base, acrescentando-se alumínio e nióbio como ligantes para estabilizar a austenita e a martensita respectivamente. O método de processamento empregado foi por fusão a plasma, pelo processo Plasma Skull Push Pull (PSPP), o qual proporciona uma atmosfera protetora de argônio (OLIVEIRA, 2007; SIMÕES, 2015).

\section{MATERIAIS E MÉTODOS}

A parte experimental consistiu em adquirir a liga de nitinol. Para isso foi comprado o fio ortodôntico industrial, o qual se trata de uma liga superelástica em temperatura ambiente e utilizado em arcos ortodônticos. Essa liga, depois de fundida em forno a plasma e caracterizada, foi utilizada como referência para as ligas acrescidas dos ligantes de nióbio e alumínio. Foram realizadas análises metalográfica, da composição química por EDS, da microdureza Vickers, além da análise térmica (DSC) e difratometria (DRX), obtendo-se assim, um experimento comparativo com a influência de novos metais para o Nitinol.

A escolha dos materiais ligantes se deu pela já existência de materiais com memória de forma utilizando o alumínio, aliado a capacidade do nióbio em ser um elemento alfa estabilizador. 
O fio ortodôntico de nitinol foi pesado e levado ao forno a plasma Discovery. O forno conta com um comando computadorizado, o que facilita sua operação, bastando informar o tipo de material e sua massa para que possa ser calculado o tempo de fusão necessário.

Foi realizada ainda a fusão do fio ortodôntico de nitinol juntamente com alumínio e nióbio, o qual segue na tabela 1 a massa de material utilizada em cada Corpo de Prova (CDP). No presente trabalho, foi fixado uma massa para o Al, a fim de se obter parâmetros referentes a variação do nióbio.

Tabela 1: Massa metálica fundida no forno a plasma.

\begin{tabular}{cccc}
\hline \multirow{2}{*}{ Material } & \multicolumn{3}{c}{ Massa (g) } \\
\cline { 2 - 4 } & CDP 1 & CDP 2 & CDP 3 \\
\hline Nitinol & 2 & 2 & 2 \\
Alumínio & - & 2 & 2 \\
Nióbio & - & 0,5 & 1 \\
\hline
\end{tabular}

Para auxiliar na análise metalográfica, e no ensaio de microdureza, as amostras foram cortadas e embutidas em baquelite. As amostras foram devidamente lixadas, polidas e atacadas com ácido fluorídrico $0,5 \% \mathrm{v} / \mathrm{v}$ para posteriormente ser levada ao microscópio ótico.

Após o ataque químico, as amostras foram secas e levadas para a análise metalográfica por meio do microscópio óptico. Foram utilizadas lentes de $40 \times, 100 \times, 200 \times$ e $500 \times$ de ampliação, para a obtenção de imagens da superfície da amostra. O equipamento utilizado foi o Microscópio Opton, no Laboratório de Metalografia da Universidade Federal de Itajubá campus Itabira.

A microscopia eletrônica de varredura (MEV) foi utilizada para caracterização morfológica. Para a análise química das ligas com Nitinol, utilizou-se a espectroscopia de energia dispersiva de raios-X (EDS). Observou-se ainda a influência dos metais acrescidos à liga, sendo que para tais análises, aproveitou-se a preparação realizada para a análise metalográfica. Utilizou-se o MEV da marca TESCAN modelo VEGA3 BS.

$\mathrm{O}$ ciclo térmico utilizado para a análise de DSC teve o intervalo observado entre $-70^{\circ} \mathrm{C}$ a $100^{\circ} \mathrm{C}$, com taxa de aquecimento e taxa de resfriamento constante de $10^{\circ} \mathrm{C} / \mathrm{min}$.

A análise de DRX foi realizada na Universidade Federal de São Carlos (UFSCar). Os difratogramas foram realizados a uma varredura rápida e longa que começou no ângulo de difração $(2 \Theta)$ de $30^{\circ}$ até $120^{\circ}$, com um tamanho de passo de $0,02^{\circ}$ e tempo de contagem em cada passo de 0,25 segundo. 


\section{RESULTADOS E DISCUSSÕES}

Foram obtidos resultados metalográficos para os três corpos de prova, no qual se buscou obter informações quanto às fases presentes nas ligas. Na figura 1pode-se observar a metalografia do CDP1, que possui apenas o nitinol puro. É possível observar alguns contornos de grãos da liga e a presença de alguns pontos mais escuros representando a fase martensita.

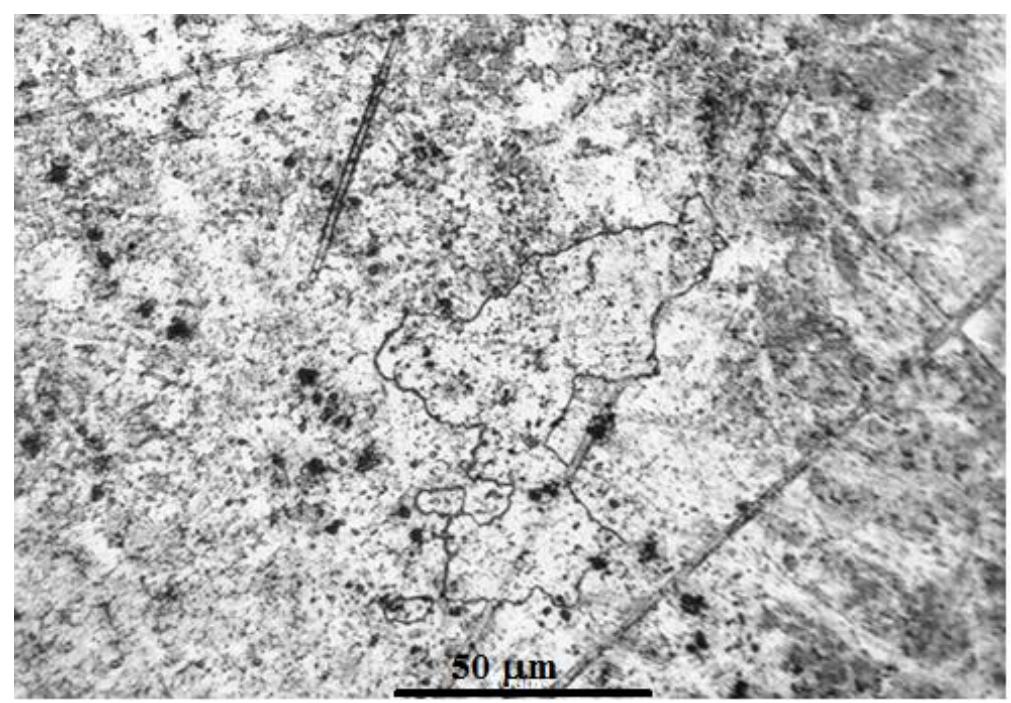

Figura 1 - Microscopia óptica do corpo de prova 1 aumentada em 200x.

Já o CDP2 apresentou uma estrutura bastante porosa o que dificultou a identificação do percentual de fases presentes através da técnica de análise ótica de imagens, como pode ser observado pela Figura 2. Não foi possível perceber e diferenciar as fases presentes na estrutura.

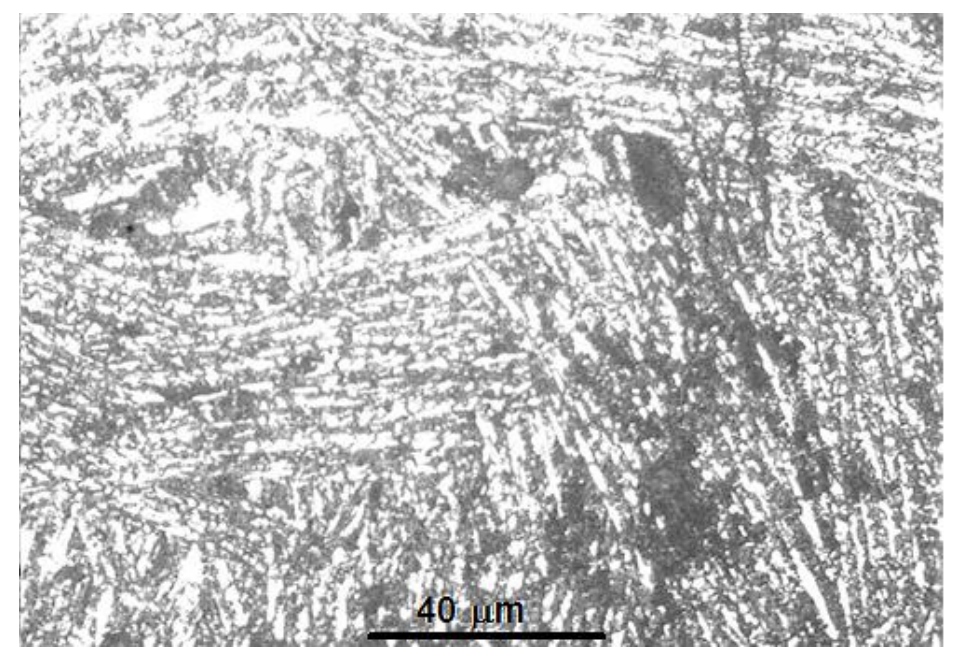

Figura 2 - Microscopia óptica do corpo de prova 2 aumentada em 100x. 
Comparando-se as Figuras 1 e 2, percebe-se que a presença dos ligantes geraram também uma influência superficial na liga, já que no caso da figura 2 deixa de existir a homogeneidade presente na amostra do nitinol puro. Assim como no CDP2, houve dificuldades para se identificar as fases presentes pela microscopia óptica graças a grande quantidade de poros presentes no CDP3, o que pode ser observado na Figura 3.

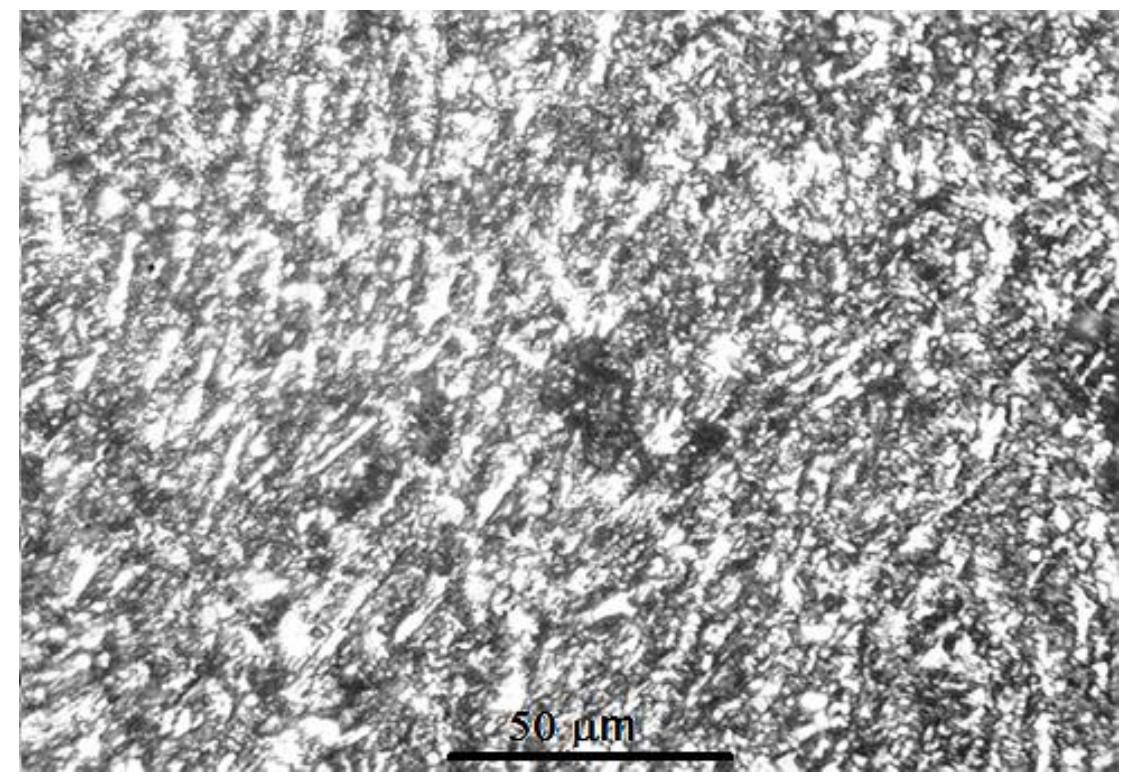

Figura 3 - Microscopia óptica do corpo de prova 2 aumentada em 100x.

Comparando-se as Figuras 1 e 2, percebe-se que a presença dos ligantes geraram também uma influência superficial na liga, já que no caso da figura 2 deixa de existir a homogeneidade presente na amostra do nitinol puro.

Assim como no CDP2, houve dificuldades para se identificar as fases presentes pela microscopia óptica graças a grande quantidade de poros presentes no CDP3, o que pode ser observado na Figura 3.

Comparando-se as Figuras 2 e 3, percebe-se que existem menores concentrações dos pontos mais escuros, o podendo-se inferir que o nióbio reduz a porosidade do material, porém ainda é um material mais heterogêneo, quando comparado com a Figura 1.

As amostras levadas ao Microdurômetro Vickers foram submetidas forças de 100gf, $200 \mathrm{gf}$ e $300 \mathrm{gf}$, em três regiões diferentes do corpo de prova. Os valores com as médias obtidas foram disponibilizados na tabela 2 , em que é possível observar que na temperatura ambiente a liga de Nitinol puro, presente no CDP 1, apresenta dureza de aproximadamente $302 \mathrm{HV}$, o que de acordo com Villarinho, et al. (2010), o resultado indica o comportamento 
mais superelástico da liga, nessa temperatura. Sendo assim, está presente $50 \%$ ou mais de austenita do que martensita no material.

Ainda de acordo com Villarinho et al. (2010), a dureza tende a aumentar com a elevação da temperatura, até atingir a completa transformação da austenita (Af). Sendo assim, pode-se inferir que em temperaturas próximas a ambiente, o Nitinol acrescido de alumínio e nióbio, presentes nos CDPs 2 e 3, podem ter comportamento semelhante ao dos metais comuns, com deformação plástica e deslizamento de planos.

Pode-se ainda justificar o aumento da microdureza pela inserção de nióbio na liga, já que de acordo com Minami(2016), pequenas concentrações do metal fazem com que provavelmente, haja aumento no teor de ligante, estabilizando mais rápido a austenita.

\begin{tabular}{ccccc}
\hline Amostra & \multicolumn{3}{c}{ Dureza (HV) } & Média \\
& 100gf & 200gf & 300gf & \\
\hline CDP 1 & $310 \pm 11$ & $302 \pm 5$ & $295 \pm 6$ & $302 \pm 5$ \\
CDP 2 & $472 \pm 26$ & $458 \pm 16$ & $537 \pm 24$ & $489 \pm 32$ \\
CDP 3 & $557 \pm 40$ & $669 \pm 42$ & $537 \pm 20$ & $588 \pm 54$ \\
\hline
\end{tabular}

Tabela 2 - Microdureza das ligas de nitinol.

Pela análise de DSC foi possível determinar-se as temperaturas de transição de fase da martensita e austenita.

Através da Figura 4, tem-se que o corpo de prova 1, em seu aquecimento, inicia a transformação reversa de martensita para austenita na temperatura de $25,9^{\circ} \mathrm{C}$ e se torna totalmente austenítico em temperatura superior a $27,1^{\circ} \mathrm{C}$. Esses valores foram obtidos ao se interpolarem as linhas de tendência de base e de pico, que no caso foi endotérmico, indicando, assim, a absorção de calor para transformação da fase martensita para austenita. 


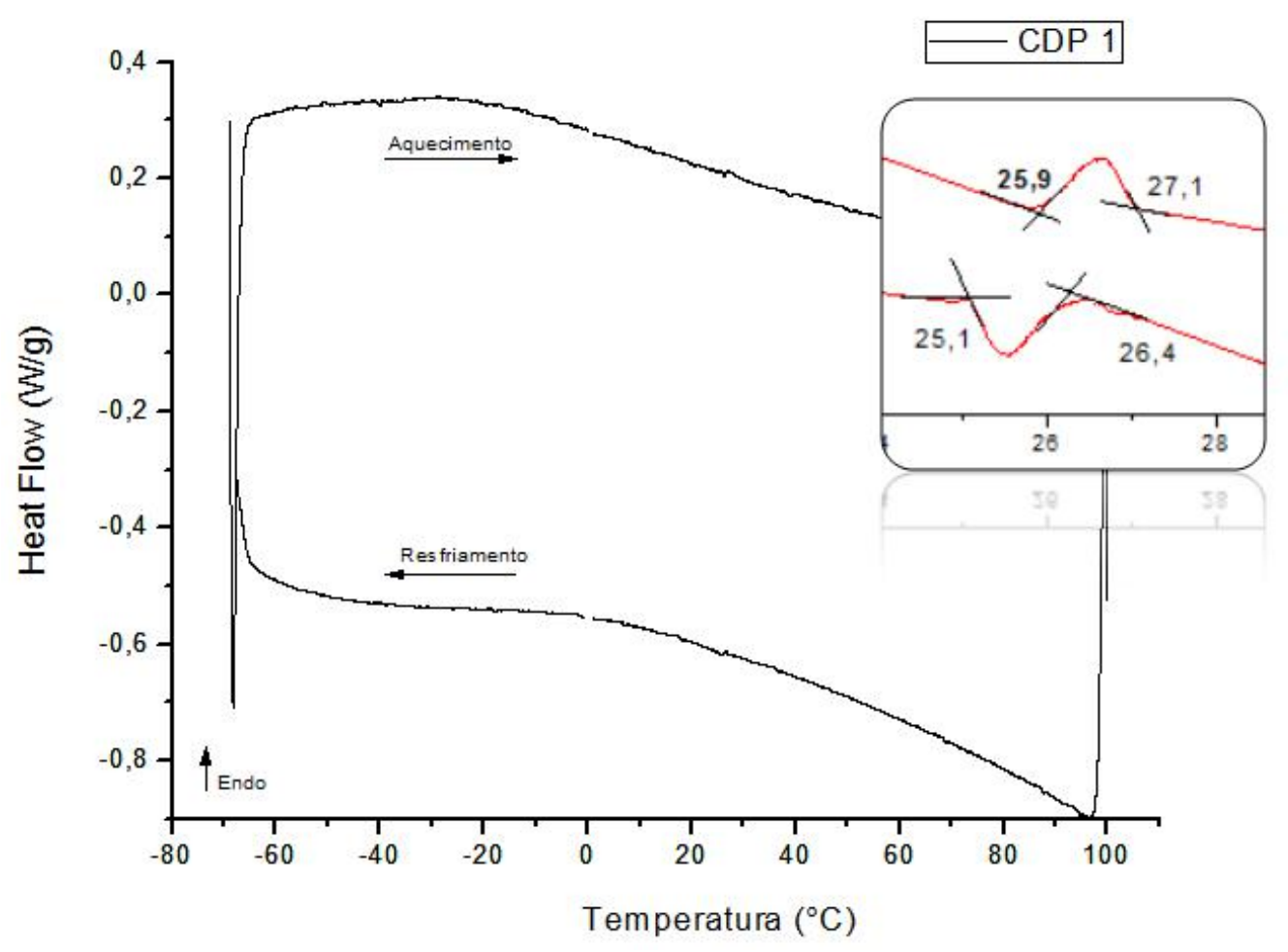

Figura 4 - Curvas de DSC do Corpo de Prova 1.

Já na transformação direta, no resfriamento, quando o material deixa de ser austenítico para se transformar em martensítico, a transformação se iniciou em $26,4^{\circ} \mathrm{C}$ e foi concluída em $25,1^{\circ} \mathrm{C}$.

A partir das informações de transição de fase obtidas no DSC, torna-se possível avaliar a histerese térmica do material, subtraindo o valor da temperatura de aquecimento pelo valor obtido de resfriamento, no momento em que o material é 50\% de uma das fases, obtendo-se assim, nesse caso do nitinol puro, o valor de $1,01^{\circ} \mathrm{C}$. Para Otsuka (2005), o valor de histerese pode ser influenciado pela capacidade de encruamento da liga, o qual é favorecido pela maior presença de níquel, o que pela análise de EDS não foi constatado. Portanto, por se tratar de uma amostra rica em titânio, o baixo valor de histerese é esperado.

Pela Figura 5, tem-se que o corpo de prova 2, em seu aquecimento, inicia a transformação reversa de martensita para austenita na temperatura de $26,2^{\circ} \mathrm{C}$ e se torna totalmente austenítico em temperatura superior a $27,6^{\circ} \mathrm{C}$. Já na transformação direta, ou seja, no resfriamento, o material começa a se tornar martensítico em $26,6^{\circ}$ e termina a transformação a $25,1^{\circ} \mathrm{C}$. Portanto, a histerese que pode ser calculada pelo mesmo modo que o corpo de prova 1 , foi de $1,56^{\circ} \mathrm{C}$.

Com os valores de temperatura de transformação e de histerese encontrados no corpo de prova 2, percebeu-se que não houve apreciável influência dos materiais ligantes, no nitinol. 


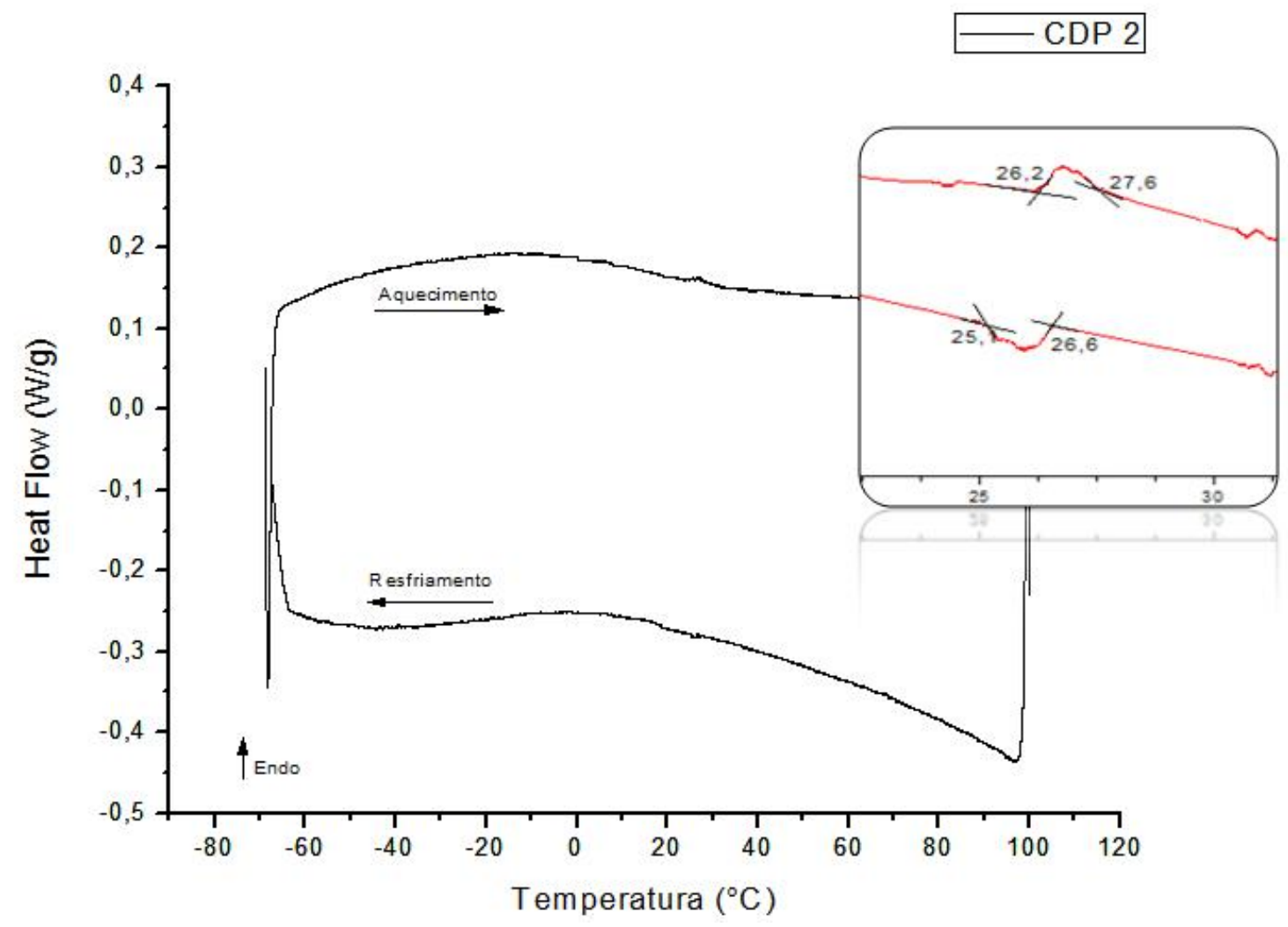

Figura 5 - Curvas de DSC do Corpo de Prova 2.

Pela Figura 6, tem-se que o corpo de prova 3, em seu aquecimento, inicia a transformação reversa de martensita para austenita na temperatura de $18,4^{\circ} \mathrm{C}$ e se torna totalmente austenítico em temperatura superior a $20,3^{\circ} \mathrm{C}$. Já na transformação direta, o material começa a se tornar martensítico em $18,6^{\circ}$ e terminar em $16,3^{\circ} \mathrm{C}$. Portanto, a histerese, que foi calculada, teve valor de $1,18^{\circ} \mathrm{C}$. 


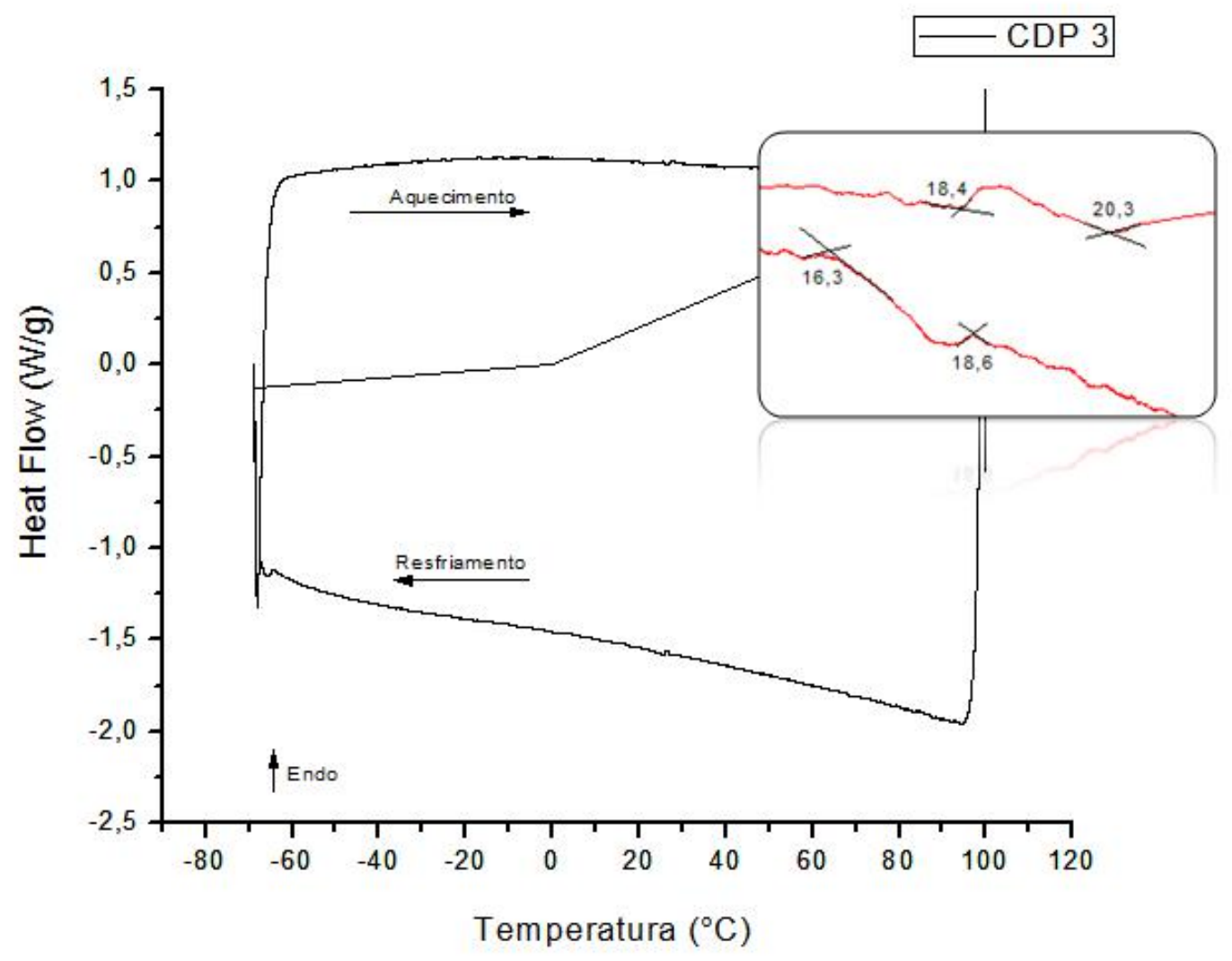

Figura 6 - Curvas de DSC do Corpo de Prova 3.

Com os valores de temperatura de transformação e de histerese encontrados no corpo de prova 3, percebe-se que a presença do ligante nióbio gerou considerável influência na liga. De acordo com o ensaio de microdureza Vickers, o CDP 3 possui maior dureza, o que pode estar relacionada com uma maior presença de nióbio, que é um ligante $\beta$-estabilizador (TADDEI et al., 2004). A influência desse fato é o deslocamento da temperatura de transformação para menores temperaturas, principalmente na transformação da austenita final, o que pode ser comprovado pelo ensaio realizado. $O$ valor de histerese não sofreu considerável alteração, o que se supõe que nessas concentrações o alumínio e o nióbio não geram impacto sobre essa propriedade. A Tabela 3 traz os valores de transformação de fase de cada um dos corpos de prova, além dos valores de histerese. 
Tabela 3 - Temperaturas de transformação de fase das ligas produzidas

\begin{tabular}{cccccc}
\hline \multirow{2}{*}{ Corpos de Prova } & \multicolumn{5}{c}{ Temperatura de transformação $\left({ }^{\circ} \mathbf{C}\right)$} \\
\cline { 2 - 6 } & $\boldsymbol{M}_{\boldsymbol{f}}$ & $\boldsymbol{M}_{\boldsymbol{i}}$ & $\boldsymbol{A}_{\boldsymbol{i}}$ & $\boldsymbol{A}_{\boldsymbol{f}}$ & Histerese \\
\hline CDP 1 & 25,1 & 26,4 & 25,9 & 27,1 & 1,01 \\
CDP 2 & 25 & 26,6 & 26,2 & 27,6 & 1,56 \\
CDP 3 & 16,3 & 18,6 & 18,4 & 20,3 & 1,18 \\
\hline
\end{tabular}

A informação inicial observada na Tabela 3 é a da temperatura Af final de transformação austenítica, a qual indica que se pode trabalhar com a pseudoelasticidade das três ligas a partir da temperatura ambiente. De acordo com Duerig et al. (1990), a superelasticidade acontece entre $25^{\circ} \mathrm{C}$ e $50^{\circ} \mathrm{C}$, acima de Af, o que representa um resultado satisfatório para os corpos de prova 1 e 2 .

É possível perceber também pela Tabela 3, que a histerese formada pela diferença de temperaturas de transição é pequena. Para Sashihara (2007), o ciclo com baixa histerese tem boa aplicação em sensores e atuadores térmicos, já que deve ter rápida "performance" na transformação de forma.

As fases presentes nas amostras das ligas produzidas foram analisadas por difração de raios X no Departamento de Engenharia de Materiais na Universidade Federal de São Carlos (UFSCAR). Os difratogramas foram realizados a uma varredura rápida e longa que começou no ângulo de difração $(2 \Theta)$ de $30^{\circ}$ até $120^{\circ}$, com um tamanho de passo de $0,02^{\circ}$ e tempo de contagem em cada passo de 0,25 segundo. Os resultados obtidos estão apresentados na figura 7.

A amostra com a composição de nitinol puro (CDP1) apresentou os picos de difração bem definidos em (110) para austenita com $2 \Theta$ de $42,5^{\circ}$, em (211) para austenita com $2 \Theta$ de $79,0^{\circ}$ e em (202) para martensita com $2 \Theta$ de 65, $0^{\circ}$ (Iijima et al., 2003; Thayer et al., 1995). Este difratograma serviu como referência para a análise dos difratogramas apresentados para as demais amostras produzidas.

No difratograma do CDP2, pode-se observar que os picos encontrados em relação ao difratograma da amostra 1, foram intensificados, em grande parte se atribui a isso a sobreposição de sinais entre o alumínio e titânio pelo acréscimo de alumínio ao nitinol (banco de dados do Jade versão 5).

No CDP3, além dos picos presentes no CDP1 e no CDP2, também, observou-se a presença de um novo pico (220) para a austenita mais acentuado, o que pode ser relacionado ao aumento de nióbio na amostra e seu efeito estabilizador da fase $\beta$ (Iijima et al., 2003; Thayer et al., 1995). 


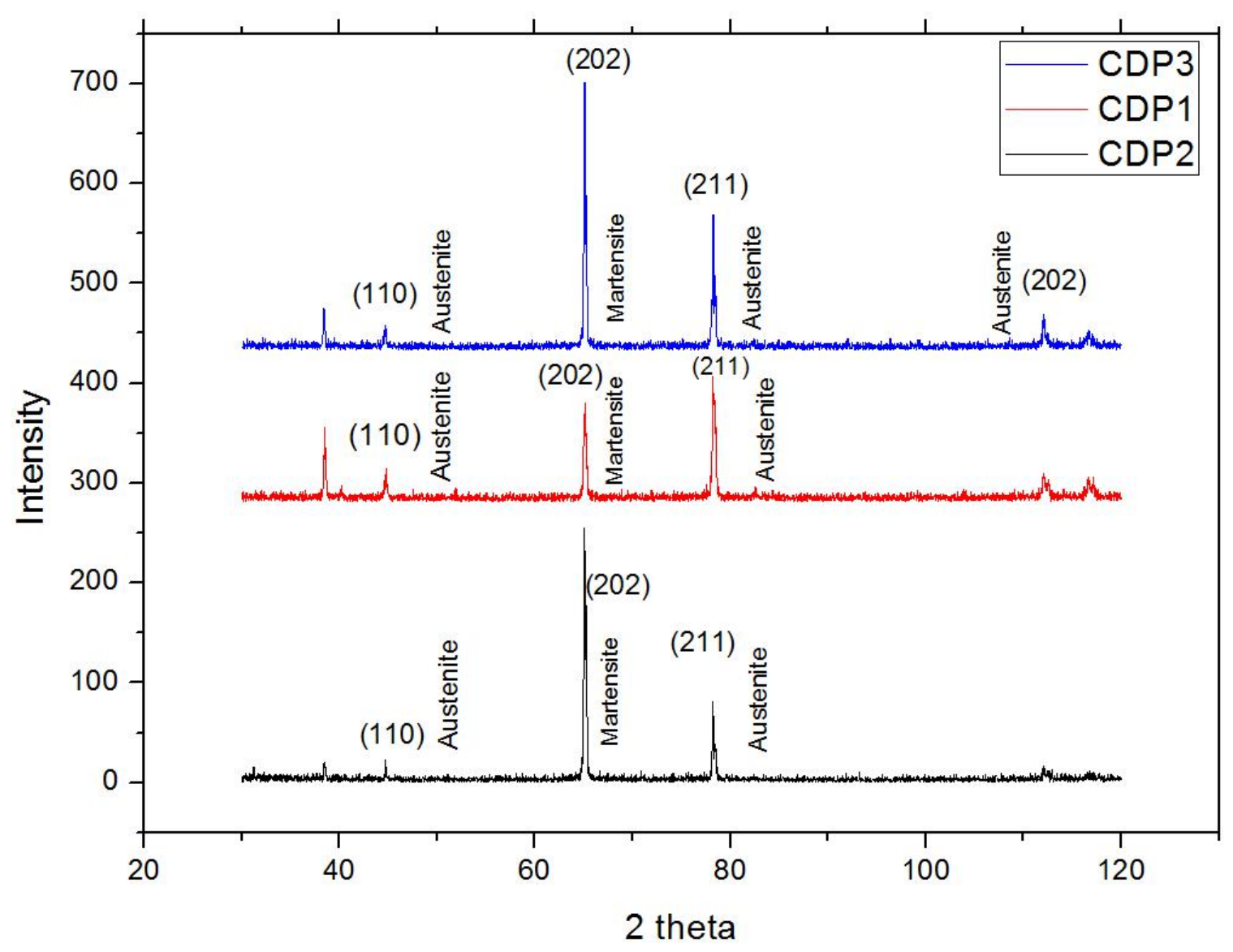

Figura 7 - Análises de DRX.

\section{CONCLUSÃO}

O presente trabalho mostrou que a inserção de metais estabilizadores das fases austenita e martensita mantém a memória de forma ao nitinol, sendo que o nióbio, elemento $\beta$-estabilizador, desloca a temperatura de transformação pra menores valores. Percebeu-se que a maior concentração de nióbio proporciona maior dureza ao material, já que o ligante estabiliza melhor a austenita, e reduz a temperatura de transformação de fase. Percebeu-se ainda nos materiais analisados que a histerese é baixa, o que se permite conduzir pesquisas com o novo material para áreas de aplicação em sensores e atuadores, já que a baixa histerese implica em rápida performance na transformação de forma. 


\section{AGRADECIMENTOS}

Os autores agradecem à FAPEMIG pelo auxílio financeiro, ao GPESE grupo de pesquisa da UNIFEI-Itabira e ao laboratório de materiais avançados LIMAV da UNIFEI Itabira.

\section{REFERÊNCIAS}

ASTM F2004-00, Standard Test Method for Transformation Temperature of NickelTitanium Alloys by Thermal Analysis, ASTM International, West Conshohocken, PA, 2000, www.astm.org

DUERIG T. W, PELTON A. R. Ti-Ni shape memory alloys. Materials Properties

Handbook, Titanium Alloys, Materials Park. OH: American Society for Metals. p. 1035-48, 1994.

IIJIMA, M; Brantley, W. A.; Kawashima, I.; Ohno, H.; Guo, W.; Yonekura, Y.; Mizoguchi, I.; Micro-X-ray diffraction observation of nickel-titanium orthodontic wires in simulated oral environment. Biomaterials, 25, 171-176, junho 2003.

LAGOUDAS DC. Shape memory alloys: modeling and engineering applications.1st ed.

New York: Springer; 2010.

MINAMI, Daichi et al. Effect of Alloying Element X on Transformation Strains and Phase Stabilities between $\alpha^{\prime \prime}$ and $\beta$ Ti-Nb-X (X=Al, Sn, Zr, Ta) Ternary Alloys from FirstPrinciples Calculations. Materials Transactions, v. 57, n. 3, p. 263-268, 2016. j

OTSUKA, K. REN, X. Physical metallurgy of Ti-Ni-based shape memory alloys, Progress in Materials Science, 50, pp. 511-678, 2005.

SASHIHARA, Eduardo Massao. Produção da liga Ni-Ti com efeito de memória de forma em forno de fusão por feixe eletrônico e sua caracterização. 134f. Tese de mestrado - Instituto de Aeronáutica, São José dos Campos, 2007.

SIMÕES, Jackson de Brito; PEREIRA, Francisco Fernando Roberto; OTUBO, Jorge; ARAÚJO, Carlos José. Caracterização térmica de uma liga de NiTi reprocessada por fusão a plasma e injeção em moldes metálicos. $70^{\circ}$ Congresso Anual da ABM, 2015 . 
TADDEI, E.B.; HENRIQUES, E.B.; SILVA, C.R.M.; CAIRO, C. A. A. Sinterização a vácuo da liga Ti-35Nb-7Zr-5Ta. Revista Brasileira de Aplicações de Vácuo, v. 23, n. 2, 68-72, 2004.

THAYER, Todd A.; Bagby, Michael D.; Moore, Robert N.; DeAngelis, Robert J.; X-ray diffraction of nitinol orthodontic arch wires. American Journal of Orthodontics and Dentofacial Orthopedics, 107, 6, junho, 1995.

VILLARINHO, Denis Jardim; ROESE, Pedro Barrionuevo; FERREIRA, Carlos; SCHAEFFER, Lírio. Caracterização parcial de liga Nitinol atuador através de pontos críticos de transformação de fases utilizando calorimetria diferencial de varredura. Estudos Tecnológicos - Vol. 6, n 1:01-10., 2010. 